\title{
Construction for the Engineering Application-Oriented Talents Training System of Building Environment and Energy Engineering in Colleges
}

\section{Tian Xingwang ${ }^{1}$, Yin Guojian ${ }^{2}$, Zhang Dianguang ${ }^{1, ~}{ }^{*}$, Dong Xiaowei ${ }^{1}$, Gao Xing ${ }^{1}$, Zhang Kun ${ }^{1}$, Li Cong ${ }^{1}$}

${ }^{1}$ School of Ocean and Civil Engineering, Dalian Ocean University, Dalian, China

${ }^{2}$ Environmental Engineering Institute. Ltd., Dalian University of Technology, Dalian, China

\section{Email address:}

txw-1203@126.com (Tian Xingwang),guojian_yin@163.com (Yin Guojian),zdz@dlou.edu.cn (Zhang Dianguang), dldxwei@163.com (Dong Xiaowei), gaoxing2002@126.com (Gao Xing), zhangk@dlou.edu.cn (Zhang Kun), licong@dlou.edu.cn (Li Cong) ${ }^{*}$ Corresponding author

To cite this article:

Tian Xingwang, Yin Guojian, Zhang Dianguang, Dong Xiaowei, Gao Xing, Zhang Kun, Li Cong. Construction for the Engineering Application-Oriented Talents Training System of Building Environment and Energy Engineering in Colleges. Science Discovery. Vol. 4, No. 3, 2016, pp. 202-206. doi: 10.11648/j.sd.20160403.18

Received: April 19, 2016; Accepted: April 21, 2016; Published: July 20, 2016

\begin{abstract}
Based on the new development requirements of application-oriented transformation for building environment and energy engineering in colleges, combined with the actual situation of Dalian Ocean University, the existing problems in the present talents cultivation mode were analyzed and summarized, and several feasible reform measures and methods were put forward to improve the construction of the professional engineering application-oriented talents training system and enhance students' engineering application ability and employability. It has important practical significance to meet the needs of active adapting to society and suit the developmental trend of the subject.
\end{abstract}

Keywords: Building Environment and Energy Engineering, Curriculum System, Application-Oriented Talents, Training Mode

\section{高校建筑环境专业工程应用型人才培养体系建设}

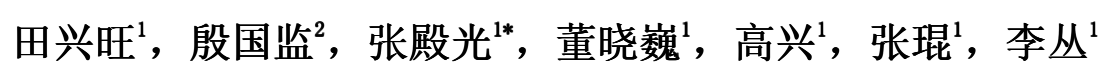

${ }^{1}$ 海洋与土木工程学院, 大连海洋大学, 大连, 中国

${ }^{2}$ 大连理工大学环境工程设计研究院, 大连, 中国

\section{邮箱}

txw-1203@126. com（田兴旺）, guojian_yin@163.com（殷国监）, zdz@dlou. edu.cn（张殿光）,

dldxwei@163.com（董晓巍）, gaoxing2002@126. com（高兴）, zhangk@dlou. edu. cn（张琨），licong@dlou. edu. cn（李丛）

摘要: 基于高校建筑环境与能源应用工程专业面临着向应用型转型新的发展要求, 结合大连海洋大学的实际情况, 对专业 现有人才培养模式中存在的问题进行分析总结, 提出几点切实可行的改革措施及方法, 以期不断完善本专业工程应用型人才 培养体系的建设, 提高学生工程应用能力和就业竞争力。这对主动适应社会需求、适应学科发展趋势具有重要的现实意义。

关键词：建筑环境，课程体系，应用型人才，培养模式 


\section{1. 引言}

目前中国的高等教育已经由精英教育阶段发展到大 众化教育阶段, 在这一发展过程中最为突出的问题便是本 科生的培养质量出现下降以及就业变得困难。同时也出现 了一种怪现象: 一方面, 高校毕业生就业十分困难; 另一 方面, 就业单位抱怨招收不到满意的人才。这一现象在建 筑环境与能源应用工程专业 (简称建筑环境专业) 也较为 突出。

经济社会的快速发展和产业结构转型优化的急剧变 革, 要求高等教育做出快速的反应。面对这个趋势, 中国各 高校掀起了新一轮的教育、教学改革, 根据自身的优势和 特色, 对专业进行新的定位, 具体改革内容和措施详见文 献 [1-7]等。以期在人才培养和教育评估中取得新的优势, 从而提高学生的工程实践能力和就业竞争力, 为国家地方 经济建设与社会发展作出贡献。

文章正是基于上述背景和目的, 以建筑环境专业的人 才培养体系建设为例, 探讨了新形势下该专业人才培养和 专业建设面临的挑战及所应采取的对策。相信这种分析对 高等工科教育, 尤其是土木建筑类专业的学科建设和人才 培养等方面具有一定的借鉴作用。

\section{2. 专业发展要求}

2012年, 教育部依据指导性专业规范 [8] 的要求, 将 建筑节能技术与工程、建筑设施智能技术（部分）、建筑 环境与设备工程合并为建筑环境与能源应用工程专业。新 建专业学习的重点是采用一系列建筑设备为建筑营造一 个健康、舒适、安全、方便的人居环境, 同时对建筑设 备的运行调节进行自动节能控制。其所涉及的课程内容更 广, 涵盖的专业知识更多, 要求工程应用实践性也进一步 增强。

中国经济的持续高速发展和建筑行业的大规模建设 需要大批高素质的本专业人才, 当前经济社会发展形势需 要部分地方本科高校向应用型转变, 社会需求决定了该专 业的发展要重新定位, 即本专业培养出来的毕业生主要从 事民用和工业建筑的设备系统工程设计、施工管理、运行 维护管理和设备销售等技术管理工作, 是具有很强的工程 实践能力和创新精神的高级应用型人才。

\section{3. 现有人才培养模式存在的问题}

大连海洋大学地处辽宁省大连市, 是一所教学研究 型的省属高校, 该校建筑环境与能源应用工程专业始建 于 2004年, 已为国家培养并输送了近300名毕业生。根 据近 3 年本专业毕业生就业数据, 就业主要方向以工程 应用性质较强的施工安装监理为主, 占毕业生总数的 $51 \%$, 其次为房地产开发和物业管理行业, 占毕业生总 数的近 $20 \%$, 有 $15 \%$ 的毕业生从事设计咨询、预算造价工 作, 还有 $8 \%$ 左右的学生选择升学深造。剩下的学生从事 其他工作。
此外, 通过走访部分大型设计施工企业, 对人才需求 状况的调研表明, 大多数企业把独立工作能力放在素质要 求第一位的最多, 占 $60 \%$; 其次是专业技能和操作能力, 占 $40 \%$; 同时对所需人才应具备敬业进取心、吃苦耐劳精 神的要求较高。通过对在校学生问卷调查表的分析显示: 大多数学生对该专业信心不足, 认为该专业处在土木建筑 类专业的末端, 地位不重要, 或认为专业课程和实践机会 少。

总之, 随着大连海洋大学的跨越式发展和专业多年来 的本科教研总结积累, 在专业建设、师资条件等方面有了 很大的提高和改善, 参考文献 [9-12]所提及的常见现象, 对学校现有人才培养模式存在的问题总结如下。

\section{1. 人才培养目标面临着向应用型专业转型的挑战}

目前建筑环境专业面临转型的重点是进一步明确办 学定位、凝练办学特色、转变办学方式, 把办学思路真正 转到服务地方经济社会发展上来, 转到产教融合校企合作 上来, 转到培养应用型人才上来, 转到增强学生就业创业 能力上来。这就需要提前做好加快转变教育思想观念、优 化专业布局结构、创新产教融合的人才培养体制机制等方 面的工作。

\section{2. 现有培养体系不利于应用型人才培养}

目前建筑环境专业的理论教学仍以讲述基本原理、系 统分析为主, 讲授过程很大程度上脱离实际工程应用这个 层面。而实践环节教学的内容老套、方式单一, 形式化严 重, 不利于发挥学生的主观能动性。此外, 对教师和学生 的考核评价机制也不完善, 这些都不利于培养出具有可塑 能力的建筑环境专业高级工程应用人才。

\section{3. 毕业生工程应用实践的综合能力欠缺}

从用人单位反馈的信息来看, 一方面毕业学生不能很 好地利用所学的专业知识, 采取有效的措施解决工程实际 问题, 工程实践适应能力不足。另一方面不能把所学的技 术知识准确的表述出来, 工程应用表达能力严重欠缺。从 学生反馈的信息来看, 认为在学校学习的专业知和实际工 作岗位要求的相差很大, 这也说明了现有的实践教学体系 并没有注意到学生所学知识的局限性和实际工作所需知 识的多样性。

\section{4. 从大型暖通招聘网站调研的情况分析}

从中国大型暖通招聘网站以 “暖通工程师” 为关键词 的搜索结果来看, 总体上来说对建筑环境专业本科生的需 求量很大, 但大部分都要求工作经验, 尤其是 3 年以上的 工作经验, 这与企业不愿意对员工进行继续教育有关, 但也说明我们培养的学生不能立即适应工作岗位。

\section{5. 教师工程经验和前沿技术知识不足}

很多专业教师, 尤其是青年教师虽然学历较高, 但是 基本上都是从校门到校门的学院派, 科研能力很强, 而科 研能力不等于工程能力更不等于教学能力。由于自身工程 
经验很缺乏, 知识储备也不跟踪工程前沿技术, 这样很难 培养出创新型科技人才。如何加强高校教师工程实践经验 积累和实践环节建设是很多高等工科院校所面临的一个 问题。

\section{6 . 校企合作的积极性不高}

由于企业和学校缺乏深度合作, 企业不清楚学生实习 内容和实习任务, 对顶岗实习学生的管理也不够重视, 实 习考核走过场。由于缺乏过程管理, 实习质量得不到保证。 而学校也缺乏规范的实习教学文件和行之有效的管理制 度, 对学生实习期间的合法权益无法保障, 对学生实习可 能遇到的意外伤害没有建立相应的保险机制。

\section{4. 相应措施及改革方案}

由前述可知, 原有的人才培养体系已经不能很好的满 足本专业现在的实际客观情况, 必须进行有针对性的改革 和创新。林健在文献 [13] 中指出 “卓越工程师教育培养计 划” ( “卓越计划”) 是为贯彻落实《国家中长期教育改革 和发展规划纲要 (2010年至2020年)》而提出的高等教育重 大改革计划。根据 “卓越计划” 的要求, 参考文献 [14-18] 提出的改革措施, 同时结合学校该专业客观情况, 从以下 方面做有益的探索。

\section{1. 构建与中国现行注册工程师制度相适应的培养目标}

由于注册工程师所涵盖的专业范围既代表了本专业 学生的主要就业领域, 同时所考试的内容也代表工程界对 所需人才知识结构的要求。因此, 可将注册工程师考试所 涉及的相关知识内容融入到人才培养方案的相关课程中, 通过调整课时、学分优化人才培养模式, 强化学生职业应 用能力的训练。具体包括以下几个环节:

\subsection{1. 专业培养计划要与注册工程师考试内容有机融合}

建筑环境专业的人才培养计划所体现的专业教育, 一 定要面对工程、面对执业资格注册制度, 为工科毕业生获 得执业资格提供基础知识和基本技能的训练, 既要提高学 生的工程实践动手能力, 又要锻炼学生获取执业资格注册 证书的能力, 从而能满足注册工程师制度对毕业生综合素 质和工程能力的基本要求。

\section{1. 2. 整合专业基础课程体系, 构建专业基础课程模块}

由于传统的专业基础课程结构松散、课程之间缺乏联系, 将专业基础课程划分为热工学模块、热工测控模块、流体力 学模块等, 便于学生能从整体的角度掌握该部分较为零碎的 知识。将同一模块的课程尽量放在相邻的学期开设, 在教学 过程中充分阐明同一模块课程之间的内在联系, 这样有利于 学生综合运用相关的知识分析和解决相应的问题。

\subsection{3. 拓宽专业课程的知识面, 适应注册工程师所要求的 知识结构特点}

执业资格考试大纲所要求的专业知识体系比现有的 专业课程体系更宽泛, 需要拓宽专业课程教学的知识面,
如增加消防、给水排水、燃气供应、冷库、绿色建筑等方 面的知识。注重引导学生的专业知识和能力结构与注册工 程师的教育要求相适应, 将新技术和重要的专业标准、规 范条文融入专业课的教学中, 并根据规范的调整及时更新 教学内容, 增加学生对专业技术知识表达能力的训练, 并 培养学生综合解决工程问题的能力。

\section{1. 4. 探索新的教学方法和手段, 培养学生工程意识}

采用新颖的教学方法、现代化的教学手段, 比如积 极收集和整理与注册工程师考试紧密相连的案例, 进行 案例教学。而课程采用仿真式注册工程师工作模拟教学, 给学生以身临其境的感觉, 激发学生学习的热情, 启发 学生独立解决的问题。借助现代教学手段的视听技术, 使课堂变得丰富而严谨, 培养学生理论联系实际的能力 和自学能力。

\section{2. 将实践课程进行深度系列化、模块化和层次化, 构建 “全过程、递进式” 的实践教学体系}

\subsection{1. 编写满足工程应用型人才培养的实践教学教材}

编写了《建筑环境设备管理》实践教材, 搭建了理论 教学和实际工程之间的桥梁, 帮助学生快速梳理并掌握专 业所涉及重要设备的类型特点、设计选型和维护管理内容。 本教材将重要设备分基础层次、重点层次和难点层次三个 层次要求 (举例见表1)。

表1 制冷压缩机设备的三个层次要求。

\begin{tabular}{|c|c|c|}
\hline \multirow{3}{*}{$\begin{array}{l}\text { 制冷压 } \\
\text { 缩机 }\end{array}$} & 基础实践层次 & $\begin{array}{l}\text { 认识各种型号的压缩机, 熟悉各类型压缩 } \\
\text { 机的工作原理、掌握描述各种压缩机的主 } \\
\text { 要性能指标、特点和热工计算。 }\end{array}$ \\
\hline & 重点实践层次 & $\begin{array}{l}\text { 正确运用各种工具对压缩机进行机械拆 } \\
\text { 装、熟悉各种压缩机组成部件的构造和作 } \\
\text { 用, 掌握常见压缩机的装配工艺流程。 }\end{array}$ \\
\hline & $\begin{array}{l}\text { 难点 (拓展) 实 } \\
\text { 践层次 }\end{array}$ & $\begin{array}{l}\text { 灵活运用所学知识准确判断压缩机的实 } \\
\text { 际运行状况, 以便调试保养、性能评价和 } \\
\text { 故障诊断排除。 }\end{array}$ \\
\hline
\end{tabular}

\subsection{2. 建立更加稳定、有效的实践教学基地}

充分利用校企合作的平台, 逐步和校外企业单位建立 了多个实习基地, 包括设计单位、施工安装单位、工程设 备单位、自控检测设备单位和专业设备生产或销售单位等, 让学生结合自己的兴趣和将来的就业意愿去相关校外企 业单位顶岗实习, 以实践教学促就业、以就业带动新的实 践教学基地建设。

\section{2. 3. 健全专业实验实训室功能, 着重培养学生实验操作 动手能力}

在现有实验教学改革的基础上, 进一步改革实验教学 内容, 创新实验教学方法, 减少验证性实验, 逐步增加设 计性、综合性和创新性的实验。通过增加新型实验仪器设 备, 加强网络和多媒体等现代化实验教学, 制定比较完善 的实验室开放制度, 健全实验室功能。相关学科实验室和 研究项目等教学资源也要向学生适度开放。 


\section{2. 4. 设计题目要求 “真题假作”, 有针对性地完善学生 的知识结构和能力结构}

采用简化的实际工程范例 “真题假作”, 不断地强化 工程实践适应能力。采取开放型的设计模式, 让学生尽可 能多地接触不同类型的实际工程设计命题。通过设计环节 要求学生掌握收集、检索和应用各种资料和文献的方法; 熟悉和专业相关的国家标准和设计施工规范; 掌握设计计 算方法、程序步骤和工程设计要点 (如设备选型与系统布 置等）。

\section{2. 5. 专业教师与企业工程师联合培养, 让学生获得建筑 设备专业基本技能训练}

通过不定期的职业规划与专业讲座, 聘请企业高级工 程师和高级管理人员参与部分专业课程教学、指导本科生 毕业设计等, 让学生更深了解建筑环境专业工作的性质、 发展现状及趋势, 熟悉建筑环境工程设计安装、施工管理 过程, 从而在建筑环境的规划、设计、施工和运营管理等 整个工程周期中受到系统全面的实习实训。

\section{3. 积极开展各类科技实践活动, 优化教师和学生的考评 机制}

将重要的课外科技、社会实践等活动列入人才培养方 案内, 鼓励学生参加各类科技竞赛活动和设计创作, 并制 定相应的指导教师和学生奖励考评机制。通过把专业教师 送到相关的设计院、施工现场去挂职锻炼, 强化教师队伍 工程职业能力建设和责任意识, 完善教师的知识结构, 同 时要优化学生的成绩评定方式, 注重学生的实践操作动手 能力所占的比重。

\section{4. 建立校企合作的可持续发展机制}

充分发掘学校自身的优势, 分析企业的需求, 调动企 业参与的积极性, 将学校的人才优势和企业的资源优势结 合起来, 建立优势互补、互惠共赢的长效合作模式。相关 利益方权责的划分包括：1）明确企业和企业指导师傅的 权责；2）学校负责制定各项管理制度, 完善顶岗实习各 环节操作流程的具体细则；3）学生在实习期间应遵守企 业和学校的规章制度, 保证操作行为的规范。

\section{5. 加强智能建筑控制辅修实践基地的建设, 培养专业交 叉应用型人才}

为了满足社会对懂得一定建筑智能化知识与技术毕 业生的需求, 也形成自己的专业特色, 大连海洋大学建筑 环境专业设置加大了对智能建筑科技人才的培养, 通过学 校和知名企业共建了建筑环境智能建筑控制辅修实践基 地, 重点培养暖通空调制冷-建筑设备学科与电气控制学 科相结合的复合工程应用型人才。

\section{5. 结束语}

文章针对大连海洋大学建筑环境专业现有人才培养 模式中的问题进行了分析, 依据 “卓越计划” 的要求, 结 合当今社会的人才需求、生源就业、专业面临者向应用型
转型的挑战等实际情况, 通过构建与注册工程师制度相对 应的培养体系, 完善实习实训方案、实习基地的建设、教 师与学生考评机制等, 加强了建筑环境专业工程应用型人 才培养体系的建设, 为提高学生的工程实践能力和就业竞 争力提供了保障。

\section{致谢}

本文感谢下面基金项目的支持: 辽宁省教育评价协会 教学改革与教育质量评价研究立项课题 (PJHYYB15117); 大连海洋大学校级课程建设立项项目; 大连海洋大学校级 教改项目。

\section{参考文献}

[1] 丁云飞, 吴会军, 朱赤晖, 徐晓宁. 建环专业 “卓越计划” 人才培养模式改革探讨. 高等建筑教育, 2013, 22（3）: 18-22

[2] 金香菊, 石婷萍. 新形势下建环专业人才培养模式探讨 [J/0L]．科 教 导 刊（下旬 ), 2015 （12） http://www. cnki. net/kcms/detail/42. 1795. N. 20160111 . 1354. 111. html

[3] 王宇, 郭春梅, 颜爱斌. 面向工程应用型人才培养的实践教 学体系研究一以建筑环境与设备工程专业为例 $[\mathrm{J}]$. 中国轻 工教育, 2014（4）：68-71

[4] 李栋, 齐晗兵, 贾永英. 建环专业CFD教学方法改革及对策 $[J]$. 长春理工大学学报 (社会科学版), 2013, 26 (8)： 201-204

[5] 王志勇, 王汉青, 冦广孝, 刘畅荣. 建筑环境与设备工程 专业空调课程群建设的研究与实践 $[J]$. 湖南工业大学学 报, 2009, 23（2）：89-91

[6] 陈晓, 李小华, 张国强, 李念平. 注册工程师制度和建筑环 境与能源应用工程专业教学改革 $[\mathrm{J}]$. 高等建筑教育, 2013, $22(6): 26-28$

[7] 张红婴, 刘伟, 罗凯. 空气调节课程 “校企联合, 项目驱动 型” 教学模式改革研究 [J]. 2014，23（2）：90-93

[8] 高等学校建筑环境与设备工程学科专业指导委员会. 高等 学校建筑环境与能源应用工程本科指导性专业规范 [M]. 北 京: 中国建筑工业出版社, 2013

[9]田兴旺, 高兴, 张殿光, 张琨. 建筑环境专业实践教学改革 方法研究 [J]. 教育教学论坛, 2014（2）：41-42

[10］刘丽蒙, 余晓平, 彭宣伟. 基于校企合作的应用本科院校实 践教学培养模式探讨一一以建筑环境与能源应用工程专业 为例 $[\mathrm{J}]$. 中国电力教育, 2013, 278（19）：139-140

[11] 谷士艳, 孙清, 敖永华, 张春梅, 高 微. 建筑环境与设备 工程专业实践教学改革探索 $[\mathrm{J}]$. 沈阳农业大学学报 (社会 科学版)，2011，13(2)：212-215 
[12］李晓虹, 苏华, 李茜, 龙翔, 陶淑彦. 建筑环境与设备工程 生产实习教改初探 [J]. 高等教育研究, 2005, 12 (4) : 70-72

[13] 林健. “卓越工程师教育培养计划” 通用标准研制 [J]. 高等工程教育研究, 2010，4：21-29

[14] 李志生, 张国强, 李念平, 陈友明, 欧阳浪琴. 建筑环境与 设备工程专业国内外发展趋势 $[\mathrm{J}]$. 高等建筑教育, 2008, 17 (1) : 1-5

[15] 张东海, 黄炜, 黄建恩. 建筑环境与设备工程专业实践教学 体系构建探讨 [J]. 高等建筑教育, 2010, 19 (6) : 127-131
[16] 余晓平, 刘丽莹, 付祥钊. 校企合作培养建环专业学生工程 能力的实践分析 $[J]$. 暖通空调, 2013,43 （8）：20-13

[17] 吴根树, 刘妍, 陈锋. 建筑环境与设备工程专业课程设计教 学模式的改革与实践 $[J]$. 北华航天工业学院学报, 2011, 21 (2) : 46-47

[18] 倪龙, 姚杨. 建筑环境与设备工程专业人才需求及培养探讨 [J]. 高等建筑教育, 2010,19 (4) : 46-50 